Result A total of 2498 (64\%) respondents completed the follow-up questionnaire; $43 \%$ were men; average age was 42 years old. Interpersonal conflict and ERI significantly and positively correlated with the increased total cost $(\mathrm{p}<0.001$, 8,278 JPY and 11,047 JPY, respectively, for 1SD change); coworker support significantly and negatively correlated $(\mathrm{p}=0.001,-10,583 \mathrm{JPY}$ for $1 \mathrm{SD}$ change). These three factors significantly correlated with lost labour cost $(p<0.001)$. ERI significantly and positively correlated with medical cost $(\mathrm{p}=0.030)$.

Discussion Poor psychosocial work conditions well predicted excess labour and medical cost at one-year follow-up. Improving interpersonal conflict, ERI, or coworker support by $1 \mathrm{SD}$ of the score would benefit for saving the total cost of 8000 to $11,000 \mathrm{JPY}$ per month.

\section{DURATION OF RETURN TO WORK AFTER MYOCARDIAL INFARCTION AND THE ASSOCIATED FACTORS AT NATIONAL CARDIOVASCULAR CENTRE HARAPAN KITA}

${ }^{1} \mathrm{~N}$ Hanifa, ${ }^{1} \mathrm{~N}$ Adi, ${ }^{2} \mathrm{~B}$ Purwowiyoto. 'Occupational Medicine Division, Community Medicine Department, Universitas Indonesia; ${ }^{2}$ Cardiology and Vascular Medicine, Universitas Indonesia

\subsection{6/oemed-2018-ICOHabstracts. 1533}

Introduction Myocardial infarction as a cardiac disease that has the highest fatality rate in Indonesia occurs in many working age population and causes temporary disability for work. Approximately 90 million working days are lost every year due to myocardial infarction. Many research showed that the unemployed condition is associated with a relative risk of mortality and increases the risk of death by almost $50 \%$. However, Indonesia that has more than fifty million workers, has no reference to the duration of return to work after myocardial infarction.

Methods This cross-sectional study was conducted at National Cardiovascular Centre Harapan Kita. 130 employed out-patients were involved to this study by consecutive sampling method. The required data was gathered from general data questionnaires, DASS 42, Job Satisfaction Survey and medical records.

Results The median for the subjects' age was 55. 93,2\% subjects were male and $6,8 \%$ were female. $74,2 \%$ subjects had sedentary job and $25,8 \%$ had an active job. Among them, $45,5 \%$ had PCI and 54,5\% had conservative treatment. The median duration for return to work was 14 days. Based on linear regression analysis, subjects with active job have longer return to work duration ( $\mathrm{p} 0.004$ ), those with $\mathrm{EF}<40 \%$ have longer return to work duration ( $p$ 0.02), and those with longer hospitalisation duration also have longer return to work duration (p 0.004). Depression, anxiety, and job satisfaction did not associated with return to work duration.

Conclusion The successful of return to work after myocardial infarction needs a precise evaluation on type of job, left ventricular ejection fraction, and hospitalisation duration by an occupational medicine specialist and cardiologist. Different from another country, psychologic factors is not associated to return to work duration after myocardial infarction in Indonesia, thus the prevention for longer disability after myocardial infarction should be focusing on clinical and occupational factors.
119 DEVELOPMENTAL EVALUATION: A FRUITFUL STRATEGY FOR IMPLEMENTING AND EVALUATING A WORK REHABILITATION PROGRAM FOR WORKERS WITH COMMON MENTAL DISORDERS

${ }^{1,2}$ Chantal Sylvain*, 1,2 Marie-José Durand, ${ }^{1,2,3}$ Astrid Velasquez-Sanchez, ${ }^{3}$ Nathalie Lessard, ${ }^{2}$ Pascale Maillette. ${ }^{1}$ Université de Sherbrooke, Longueuil, Canada; ${ }^{2}$ CAPRIT, Hôpital CharlesLe Moyne Research Centre, Longueuil, Canada; ${ }^{3}$ IIUSSS de Laval, Laval, Canada

\subsection{6/oemed-2018-ICOHabstracts.1534}

Introduction In Canada, few early work rehabilitation services are offered to prevent long-term work disability due to common mental disorders (CMD), despite population-level needs. Our study aimed to support and evaluate the implementation and effects of an innovative program designed to promote post-CMD return-to-work (RTW) in primary healthcare.

Methods A developmental evaluation approach (Patton, 2011) was retained. Main implementation strategies consisted of periodically revising the program's logic model and discussing its underlying theory of change with clinicians. Data collection tools included: dashboards of activities conducted with participants $(\mathrm{n}=41)$; interviews with participants upon discharge $(n=26)$ and 6 months post-discharge $(n=24)$; questionnaires completed by attending physicians $(n=18)$. Quantitative data underwent descriptive statistical analyses, while qualitative data underwent thematic analysis. Results were presented and discussed periodically with clinicians to ensure their credibility.

Result The implemented program included group interventions, one-on-one interventions, and concerted actions with partners. Participants began the program after 5 months of sick leave on average, and participated for $10 \pm 2$ weeks. $80 \%$ of cases included concerted actions, usually with insurers and rarely attending physicians. However, virtually all the physicians saw the program as meeting needs and promoting RTW. Active components identified by participants concerned primarily the interventions' group format, but also activities, and clinicians themselves. In terms of the program's final expected outcome, $69 \%$ of the participants returned to work upon discharge and 79\% were at work 6 months post-discharge.

Discussion The program studied is based on the best scientific evidence and is feasible in a primary healthcare context. Results suggest that it facilitates a sustainable RTW of workers with a CMD and that it supports physicians in their interventions with this population. While additional work is required to demonstrate its effectiveness, current results suggest that a group format is an important intervention component for this target population.

\section{WHAT ARE THE ACTIVE COMPONENTS OF A WORK REHABILITATION PROGRAM ACCORDING TO WORKERS SICK-LISTED FOR A COMMON MENTAL DISORDER?}

${ }^{1,2}$ Chantal Sylvain*, 1,2Marie-José Durand, ${ }^{2}$ Pascale Maillette. 'Université de Sherbrooke, Longueuil, Canada; ${ }^{2}$ CAPRIT, Hôpital Charles-Le Moyne Research Centre, Longueuil, Canada

10.1136/oemed-2018-ICOHabstracts. 1535

Introduction Common mental disorders (CMDs) are highly prevalent and a leading cause of work disability. Although specialised programs are now offered to prevent these workers from developing long-term work disability, little is known 
about their views on helpful aspects of these programs. Our study sought to describe the active components of a work rehabilitation program based on the best scientific evidence, from the participants' perspective.

Methods This study is the qualitative part of a broader research project aimed at the developmental evaluation of the program using a mixed methods approach over two years. We conducted semi-structured interviews of 26 participants after program completion. The questions concerned the program components they considered beneficial and their reasons. The interviews were conducted by telephone, recorded and analysed using thematic analysis principles. Converging themes were identified and classified by component type.

Result The active components identified concerned the interventions' group format, activities, and occupational therapists (OTs). Participants saw three benefits to the group format: it offsets the feelings of isolation and shame associated with mental disorders; allows them to adjust their view of their work disability and means for reducing it; and reactivates their social interaction skills. The activities seen as most beneficial concerned training on techniques to better cope with work and daily life (e.g. mindfulness meditation). OTs were seen as having three main functions: relaying information to physicians and other stakeholders; coaching (supporting integration of the techniques, giving meaning to the experience, pointing to external resources); and ensuring the therapeutic environment of the group interventions.

Discussion Our study results provide valuable insights into components that should be priorities if we are to ensure that work rehabilitation programs meet this population's needs. While additional work is required, current results suggest that a group format is an important intervention component for workers with CMDs.

\section{PRACTICAL TYPES OF GOOD PRACTICES FOR WORKERS WITH INTELLECTUAL DISABILITIES IN JAPANESE INDUSTRIAL WORKPLACES}

Y Sano*, N Okuta, S Saito, K Sakai. The Ohara Memorial Institute for Science of Labour, Tokyo, Japan

\subsection{6/oemed-2018-ICOHabstracts.1536}

Introduction A clear trend is seen in Japan in advancing the employment of workers with disabilities. The new amendments in 'the Act on Employment Promotion etc. of Persons with Disabilities' suggest companies to increase the rate of employment for workers with disabilities. Due to lack of knowledge and experiences, the retention rate of workers with intellectual disabilities remains low. It is necessary to extend case-based approaches for these workers relying on ongoing good practices.

Methods From the reports at the Japan Organisation for Employment of the Elderly, Persons with Disabilities and Job Seekers, 128 workplace-level good practices for supporting workers with intellectual disabilities were identified. The approaches taken by these practices were categorised into five technical areas by a team of well-experienced occupational health practitioners. We analysed common features and mutual relationships of these approaches.

Results While the size and industry of the corresponding companies were different, several key trends could be extracted from these good practices. Of 128 examples of support for workers with intellectual disabilities, 51 were about 'work methods', 28 about 'employment adjustment', 22 about 'securing work-life balance', 13 about 'improving communication' and 10 about 'workplace environment'. It was striking that the workplaces implemented these practices on plural areas. Three key trends could be thus extracted; (a) implementation of the practices covering multiple technical areas, (b) combining work methods and employment adjustment as essential areas for supporting workers with intellectual disabilities, and (c) Improving communication and workplace environment as areas further taken in advancing the support of these workers. Conclusion The extracted three key trends in good practices for workers with intellectual disabilities suggest the importance of comprehensive support measures addressing the multifaceted measures. 'Work methods' and 'employment adjustment' are essential areas for this support, and 'improving communication' and 'workplace environment' are applicable for extending the support.

\section{SUCCESS FACTORS FOR REHABILITATION AND RETURN TO WORK SYSTEMS IN THE CONTEXT OF AN AGEING WORKFORCE}

Timothy Tregenza*, Sarah Copsey. European Agency for Safety and Health at Work (EUOSHA), Bilbao, Spain

\subsection{6/oemed-2018-ICOHabstracts. 1537}

Introduction EU-OSHA initiated the Safer and healthier work at any age project in 2013 to investigate ways of improving health and safety at work considering the challenges of an ageing workforce.

Methods The project considered rehabilitation and return to work with a research review, an analysis report and nine case studies on rehabilitation/RTW programmes.

Results The analyses identified different approaches across the State systems examined, prerequisites for a successful system, and factors for a successful rehabilitation and RTW system. The research review examined prerequisites for a successful rehabilitation and return to work system. In general:

- Evidence points to the beneficial effects of work on health and well-being,

- Interventions that contain a workplace component appear to be more effective, and

- The sooner an intervention takes place, the more effective it is likely to be.

The analysis report identified common elements that contribute to effective return to work and rehabilitation systems at national and workplace levels. These included:

- A legal framework that covers all aspects of the process;

- Integration of the inclusive RTW system into a comprehensive policy framework;

- Good coordination across relevant policy areas;

- Successful interventions that are tailored to the worker;

- The use of incentive based systems without binding instruments; and

- Provision of financial and technical support

Discussion This is the first European overview on this topic. It highlights that governments should move towards a system that encourages an integrated system that focuses on workers' capabilities rather than their disabilities. 